\title{
Correlação entre comprimento de prega vocal e classificação da voz de cantores: um estudo de medidas morfológicas por meio de raios $X$
}

\author{
Enio Lopes Mello ${ }^{1}$, Marta Assumpção de Andrada e Silva ${ }^{2}$
}

Roers F, Mürbe D, Sundberg J. Predicted singers' vocal fold lengths and voice classification - a study of x-ray morphological measures. J Voice. 2009;23(4):408-13.

A presente resenha tem como objetivo discutir a correlação do comprimento das pregas vocais (PPVV), com a classificação vocal de cantores, por meio de medidas morfológicas, obtidas por raio $\mathrm{X}$.

Os autores do artigo, acima citado, partem do pressuposto que, o comprimento das PPVV é um dado particularmente relevante para cantores e que pode ser considerado como um dos principais fatores por trás da classificação vocal. Segundo os autores, este dado pode dar indícios da capacidade de extensão e alcance de uma voz, entre graves e agudos, e com isso definir o registro vocal, ou seja, predizer se a voz é de soprano, mezzo-soprano, contralto para as mulheres ou tenor, barítono, baixo para os homens.

Para realização da pesquisa eles utilizaram um banco de dados de 132 amostras de vozes de cantores, que ingressaram no curso de canto da Universidade de Música de Carl Maria von Weber de Dresden, entre os anos de 1959 a 1999. Foram selecionadas 71 vozes do sexo feminino (40 sopranos, 22 mezzo-sopranos, nove contraltos) e 61 do sexo masculino (19 tenores, 23 barítonos, 19 baixos). A faixa etária variou de 16-31 anos, idade média de 18,8 e 19,7 respectivamente. Os critérios de exclusão foram três: vozes não classificadas no inicio do curso; alunos que mudaram de classificação vocal durante o curso de formação e alunos desistentes do curso.

Os autores asseguraram que todas as imagens de raio $\mathrm{X}$ foram feitas no departamento de Radiologia do Hospital Universitário de Dresden sob condições técnicas idênticas.

As radiografias analisadas exibiram uma projeção sagital das vias aéreas superiores. Os perfis incluíram a faringe, laringe, traquéia proximal, vértebras cervicais e uma parte anterior do crânio. Também foi incluído um instrumento de metal para a medição, com calibrador de $131 \mathrm{~cm}$ de diâmetro interno, montado sobre um carrinho e localizado na frente da

(1) Pós-graduando (Doutorado) em Fonoaudiologia do Programa de Estudos Pós-graduados em Fonoaudiologia da Pontifícia Universidade Católica de São Paulo - PUC-SP - São Paulo (SP), Brasil.

(2) Doutora, Professora do Programa de Estudos Pós-graduados e do Curso de Fonoaudiologia da Faculdade de Ciências Humanas e da Saúde da Pontifícia Universidade Católica de São Paulo - PUC-SP - São Paulo (SP), Brasil; Professora Adjunto do Curso de Fonoaudiologia da Faculdade de Ciências Médicas da Santa Casa de São Paulo - FCMSCSP - São Paulo (SP), Brasil. Endereço para correspondência: Enio Lopes Mello. R. Dr. Alberto Seabra, 555, casa 04, Vl. Madalena, São Paulo (SP), Brasil, CEP: 05452-000. E-mail: enio.mello@superig.com.br linha mediana da laringe, com os sujeitos em posição ereta e com a boca fechada.

O raio central foi dorsal, com cerca de $3-5 \mathrm{~cm}$ para visualizar a proeminência da laringe. A distância do tubo e da placa de foto foi de $1 \mathrm{~m}$, e a distância entre o tubo e a faringe mediana foi de $25 \mathrm{~cm}$. Foram usadas seis válvulas de raios X (D800,TUR) com voltagem de 40-45 kV e 40-75 mA de corrente. Para melhorar o contraste eles usaram um iluminador Cool Brite (CB2, RADX, Houston, TX).

Concordamos como os autores no sentido de que, determinar com precisão o comprimento da parte membranosa (mucosa) das PPVV, entre a tireóide e a aritenóides, a partir de exames de raio $\mathrm{X}$ do perfil de indivíduos jovens é uma tarefa muito difícil. Isto porque frequentemente as cartilagens da laringe de jovens não estão calcificadas o suficiente para produzir sombra nestes exames. No entanto, na referida pesquisa, foram encontrados 29 casos, dos 132 analisados, com calcificação das cartilagens aritenóides que permitiram fazer uma estimativa do comprimento das PPVV.

Os autores fizeram duas medidas. Uma medida foi a distância, no plano sagital, entre o entalhe anterior da cartilagem tireóide e o contorno da coluna vertebral. Eles traçaram uma reta entre o contorno anterior do atlas e a parte superior da sétima vértebra até o nível da incisura da cartilagem tireóidea, que foi denominada STAP. Outra medida foi obtida a partir da medição do diâmetro antero-posterior do contorno da subglótica e traqueal, ou seja, distância entre a cartilagem tireóide e do contorno anterior da próxima vértebra cervical, o que inclui o espaço pós-cricóide, que foi denominada como distancia tiróide espinhal (TS). Esta medida variou conforme a distância até a glote. Todas as medições foram feitas sem informação da classificação vocal dos sujeitos.

Os resultados obtidos na pesquisa não permitiram conclusões confiáveis devido ao baixo numero de amostras; porém as 29 amostras consideradas demonstraram alta correlação entre o comprimento das pregas vocais com a classificação da voz.

Os autores encontraram os seguintes resultados em milímetros: média de sete sopranos, $\mathrm{STAP}=14,9$ e TS=14,7; média de oito mezzo-sopranos, $\mathrm{STAP}=16,0$ e TS=15,8; média de três contraltos, $\mathrm{STAP}=16,6$ e TS=16,6; média de cinco tenores, $\mathrm{STAP}=18,4$ e TS=18,5; média de três barítonos, $\mathrm{STAP}=19,5$ e TS=19,4; média de três baixos, $\mathrm{STAP}=20,9$ e TS=21,1.

Para ilustrar a proposição dos autores do artigo sobre o ta- 
manho das PPVV e a classificação vocal fazemos uma analogia do tamanho da PPVV humana, com instrumentos musicas de corda de uma orquestra. Ou seja, quanto maior for o tamanho do instrumento, maior é capacidade de emitir notas graves e, quanto menor o instrumento maior capacidade de emitir notas agudas, exemplos: respectivamente baixo acústico e violino.

Porém, fazemos uma ressalva: saber o comprimento (tamanho) da PPVV não basta para definir a classificação vocal. Pois, para a classificação de uma voz, segundo os aspectos morfológicos, consideramos também a massa e a tensão, ou seja, a capacidade de extensibilidade (alongamento) das PPVV, bem como as condições anatômicas e funcionais do trato vocal como um todo.

Ponderamos que, medir as PPVV de um cantor não é uma prática usual, tampouco existe consenso entre os profissionais quanto à melhor forma para fazê-lo. Além disso, sabe-se que antes mesmo da emissão vocal ocorrer, os músculos tireoaritenóideos (TA) se alteram, em decorrência da respiração, por meio da rotação e posicionamento das cartilagens aritenóides, que provocam abertura ou fechamento das PPVV, com consequentes e sucessivos alongamentos e encurtamento. Outrossim, vale salientar que na literatura da área, muitos dados sobre o tamanho das PPVV foram obtidos a partir da dissecação da laringe e extração das PPVV de cadáveres, porém na maioria dos casos, esses dados não permitiram estabelecer correlação com classificação vocal de cantores, por motivos óbvios. Por essa razão, os autores da pesquisa optaram por analisar as ra- diografias em que os sujeitos estavam em apnéia e sem fonação.

Nossas considerações sobre o assunto assumem uma postura cautelosa. Não podemos e não devemos afirmar que o comprimento (tamanho) ou a forma de um músculo define a função elou a qualidade de qualquer ação ou movimento. A qualidade de uma voz depende da fonte produtora (PPVV) e do filtro (estruturas acima das PPVV), que são as caixas de ressonância e que podem modificar os sons produzidos. Portanto, a voz que ouvimos não é, de forma alguma, determinada exclusivamente pelas PPVV, ela é uma combinação da ação da fonte (PPVV) com o filtro e a sua frequência é determinada pela massa, comprimento e tensão PPVV.

Além das questões fisiológicas descritas acima, existem outros fatores a serem considerados para a classificação vocal, como por exemplo: idade, condições sócio culturais, saúde geral (alterações hormonais, endócrinas, problemas em vias áreas superiores e inferiores, entre outros), hábitos relacionados a saúde vocal (fumo, álcool, alimentação, hidratação etc.) e inclusive aspectos de ordem psíquica.

Devemos considerar também, no caso dos cantores, a possibilidade de mudança de classificação vocal em decorrência da experiência e das técnicas de canto. Elas permitem ao cantor fazer ajustes no trato vocal, para emitir sons de acordo com o repertório ou necessidades, sem que isso cause prejuízo ao aparelho fonador. Neste sentido, consideramos que embora o comprimento (tamanho) das PPVV seja um dado importante para classificação vocal, isoladamente ele não é determinante. 